Test Method

\title{
Mechanical and Optical Characterization of a Tissue Surrogate Polymer Gel
}

\author{
R.K.A. Pasumarthy and H.V. Tippur \\ Department of Mechanical Engineering \\ Auburn University, AL 36849
}

\begin{abstract}
The mechanical and optical characteristics of a transparent tissue surrogate ballistic polymer gel were measured at different loading rates. This included measurement of tension and shear responses of the gel. Due to the compliant nature of the material, special strategies had to be developed for sample preparation, specimen gripping and deformation measurement. The digital speckle correlation method was used for measuring 2D strains in uniaxial tension tests. Subsequently, the Mooney-Rivlin description was used to extract the material characteristics from measured stress-strain data. Using a newly introduced optical method called Digital Gradient Sensing (DGS), the elasto-optical constants for the material were evaluated at different loading rates.
\end{abstract}

Keywords: polymer gel, mechanical testing, optical metrology, mechanical properties, optical constants

\section{Introduction}

Polymer gels are often used to mimic the mechanical behavior of biological tissue. In the field of terminal ballistics, they are used to test the effectiveness of firearms where the primary focus is on the depth of penetration of a projectile into the living tissue [1, 2]. Using gels, the wildlife management and hunting communities have also developed broad knowledge for adequate ammunition to incapacitate animals [3]. Tissue surrogates also play a vital role in mimicking the effects of soft tissue to extreme pressures and velocities $[4,5]$ since blunt trauma affects internal organs, and hence is important for designing protective equipment including body armor. Gels can also be used as breast tissue phantom for automating early cancer detection devices [6].

The composition of polymer gels selected in such studies is usually based on certain natural tissue whose response is to be replicated. They can simulate various types of soft living tissue through tailoring of physical and mechanical properties [7]. Further, they are preferred 
over hydrogels which have disadvantages such as short shelf life, need for low temperature storage, water evaporation even at room temperature and/or long duration experiments, water seepage from samples during tests [8], to name a few. Polymer gels on the other hand offer environmental stability, they are easy to store and have longer shelf life besides being reusable by melting.

A brief review of previous reports on gels and their applications is as follows: Subhash et al. [9] employed dumbbell tensile specimen configuration to study agarose gels to obtain both axial and lateral strains using digital image correlation. They observed that both tensile strength and modulus increased linearly with an increase in agarose concentration. Sallaway et al. [6] used mechanical indentation of a tissue phantom made of a hydrogel with an embedded rigid spherical inclusion to simulate breast mass. An array of indents made by a rigid indenter over the surface of the phantom was used for measuring force as a function of indentation depth, create a spatial map of apparent stiffness, and infer the presence of 'tumor' in the surrogate. Resistance to puncture is another aspect of soft tissue surrogate investigations. Tomlinson and Taylor [10] have examined the feasibility of photoelasticity to visualize and quantify stresses due to needle insertion into different soft tissue surrogates. Some investigators have contrasted rounded probes relative to sharp medical needles for studying the puncture resistance [11]. Puncture is shown to occur suddenly after reaching the failure strain in the former, whereas the same is gradual in the latter due to a cutting response. Modeling forces during needle insertion into soft tissue is also very important to simulate surgical procedures and robot assisted surgery. Okamura et al. [12] have used a single DOF robot equipped with a load-cell and needle attachments to obtain forcedisplacement data during tests. During needle insertion into bovine liver tissue, they observed multiple peaks in the force-displacement response with the first peak corresponding to the initial puncture, and subsequent ones due to tissues inhomogeneity and other interior structures such as veins and arteries. Shan et al. [13] used the similarity in force vs displacement responses of PVA hydrogel and porcine liver to study the effects of needle sizes, shapes and tip geometries. DiMaio and Salcudean have described a grid-based method for estimating the force distribution along a needle shaft during insertion [14] into tissue.

Mechanical and optical characteristics of ballistic polymer gels are generally proprietary or unreported so not useful as tissue surrogates in scientific investigations. Gels also pose numerous challenges when traditional mechanical testing techniques are used, requiring 
extraordinary care to grip samples and avoid premature failure. In this context, mechanical characterization followed by optical evaluation of a commercially procured polymer ballistic gel was undertaken in this work. As the gel studied here has excellent transparency, full-field optical measurement techniques can be utilized for visualizing and quantifying mechanical quantities when subjected to mechanical loads. The feasibility of a relatively new optical technique called Digital Gradient Sensing (DGS) method, sensitive to angular deflections of light rays passing through the transparent polymer gel under stress, was evaluated and results related to the stress gradients for possible adaptation of the methodology and the gel for experimental mechanics studies as a tissue surrogate.

\section{Material Description}

The material employed in this research was a $20 \%$ ballistic polymer gel (from Clear Ballistics, LLC; mass density $\sim 866 \mathrm{~kg} / \mathrm{m}^{3}$ ) with a proprietary composition. Hence, Fourier Transform Infrared Spectroscopy (FTIR) $[15,16]$ was carried out to first gain insight into its composition. The results showed that the gel had a close chemical match with Tygon soft tubing material which is highly flexible and has good chemical resistance. Due to its excellent optical transparency, the polymer gel was also tested for its refractive index $(n)$ using an Abbe refractometer. The value of refractive index thus obtained was $1.4750 \pm 0.0008$.

\section{Tensile Tests}

Tension tests were conducted to determine the elastic and failure properties of the polymer gel. Dumbbell specimens of dimensions shown in Fig. 1 were employed in these tests. The cross-section of the gage section was a rectangle $\left(13 \times 6 \mathrm{~mm}^{2}\right)$, suitable to implement optical measurements on one of the $55 \times 13 \mathrm{~mm}^{2}$ faces. The sample preparation started with melting the required amount of gel to cast a constant thickness $(6 \mathrm{~mm})$ void-free sheet in fresh polycarbonate molds. A pair of metal foil cutter strips were machined and bent to dumbbell shape of required dimensions. One edge of each cutter strip was sharpened, heated to $80{ }^{\circ} \mathrm{C}$, and pressed into the gel sheet in the thickness direction. Dumbbell shaped gel specimens thus obtained are shown in Fig. 1. 
The polymer gel being very soft and compliant, direct gripping of the sample in standard (steel) grips caused the sample's skin to perforate and fail prematurely within the grips. Therefore, alternative gripping solutions were developed. The successful one had polycarbonate end tabs matching the width of the sample ends but longer and glued to the dumbbell specimen, as shown in Fig. 1. Different glues and end tab shapes/dimensions were experimented with and Loctite 401 was found satisfactory. Between the end tabs at each end of the specimen, spacers, also made of polycarbonate and of the same thickness as that of the sample, were used. A 3-4 mm gap was maintained between the end of the gel sample and the spacer. The spacers prevented thickness wise compression of the gel specimen in the end tab region. The entire arrangement was gripped in the testing machine with the load bearing surface matching the spacers.

The axial and transverse strains of the sample were measured during tensile tests using 2D Digital Image Correlation (DIC) [17]. Implementation of DIC required a random black and white speckle pattern applied to the surface of the test specimen. Unlike conventional materials where alternative black and white mists of spray paint are used, special care had to be exercised for gel samples. An acrylic ink (FW Acrylic Artists' Ink) was used for decorating samples with random speckles on one of the $55 \times 13 \mathrm{~mm}^{2}$ faces. Due to low stiffness of the material, the low viscosity acrylic ink was preferred over conventional spray paint to mitigate material reinforcement effects. Further, disjointed speckles were deposited to minimize substrate reinforcement. Since the gel samples had good transparency, only black ink was sufficient to create good quality speckles.

To determine the most appropriate speckle pattern application technique, different methods such as (a) random pattern printed with black ink on a white paper transferred to the sample, (b) manually create random dots on the sample surface with a marker, (c) spray ink using an air brush operated at different compressor pressures, (d) plucking the bristles of a tooth brush dipped in acrylic ink, were tried. Method (d) was found to produce satisfactory results. A clean brush was partly dipped in ink and brought close to the sample surface before plucking the bristles manually to spray ink on to the sample surface. After some trials, the amount of ink and the distance between the sample and brush were optimized to achieve desired speckle size. 
A photograph of the experimental setup used during tension tests is shown in Fig. 2. It consisted of a uniformly illuminated dumbbell shaped sample coated with speckles, LED lamps and a digital camera. (The cool LED lights helped minimize heating of the sample during tests.) It also shows the tension samples gripped in an Instron 4465 universal testing machine that was fitted with a $50 \mathrm{~N}$ load cell. The samples were subjected to uniaxial tension at different crosshead speeds of 0.02, 0.2, and $2 \mathrm{~mm} / \mathrm{sec}$. A digital camera (Grasshopper3 GS3-U3-41C6M; 2048×2048 pixels; 10 bit) fitted with a macro zoom lens was used to record the speckles. The digital camera was focused on the speckles and the reference speckle image was recorded under no-load condition. The crosshead was displaced at different speeds and speckle images were recorded using time-lapse photography (4-10 frames/sec) until the samples failed. The digitized speckle images recorded at different load levels were correlated with the reference image using digital image correlation software, ARAMIS.

Special considerations were necessary to track deformations using 2D DIC. The final length of the sample in the axial direction was about three times the initial length. Therefore, in order to achieve correlation until the last stage of deformation (failure), the sub-image chosen was rectangular with 3:1 ratio of pixels in the $x$ - and $y$-directions, with latter being the loading direction. Thus, the sub-images which were initially rectangular deformed into approximately square sub-images towards the last stages of deformation. After several trials with sub-images sizes and pixel overlaps, $105 \times 35$ pixel sub-images with a 20 pixel overlap was chosen. Further, as the sample deformations were large, the image analysis software could not correlate over the entire deformation history with the initial undeformed image as the reference image. Hence, each image was used as the reference image for the next.

Figure 3 shows the effect of crosshead speed on the axial stress-strain response. With an increase in the crosshead speed, and hence the strain rate, the gel material showed a stiffer response as well as an increase in the ultimate stress. Interestingly, the failure strain also increased with increase in crosshead speed. The behavior was highly repeatable with multiple samples tested for each loading rate. Unlike other conventional engineering materials, including many glassy polymers which show a reduction in failure strain but an increase in ultimate stress with strain rate, this is an unusual behavior of this polymer gel. A similar response has been 
reported by Moy et al. [8] who studied a hydrogel (20\% by mass 250 bloom type-A ordinance gelatin with $40^{\circ} \mathrm{C}$ ultrapure filtered water).

\section{Experimental repeatability and Crosscheck}

The repeatability of experiments was investigated by performing tension tests on multiple dumbbell specimens. The experiment was performed with the setup shown earlier. Images were recorded at $10 \mathrm{frames} / \mathrm{sec}$ and at a crosshead speed of $2 \mathrm{~mm} / \mathrm{sec}$. The sub-image size selected was 120 x 40 pixels, and sub-image step (overlap) was 25 pixels, so that all the images could be correlated until failure. The axial stress was calculated from the load-cell data and initial sample dimensions, whereas axial strains were obtained from DIC. These responses are plotted in Fig. 4(a). It can be observed that there is good agreement between the three tests, and hence are quite repeatable.

The material studied is a highly compliant gel, and atypical measurement and gripping strategies were employed during experiments, an independent evaluation of strains was also undertaken. This allowed checking axial strains from DIC before using transverse strains for Poisson's ratio evaluation. The crosshead axial strain measured from DIC is overlaid on those obtained from the crosshead displacement data and the initial gage length of the sample in Fig. 4(b). Good agreement between the two responses shows that there is no slipping of the sample within the end tabs, and strains measured from DIC are reliable.

\section{Tensile Characteristics}

The engineering stress-strain responses in Fig. 3 show the polymer gel exhibiting nonlinear rubbery behavior. Accordingly, the material response was modeled as a hyperelastic material. Three commonly used hyperelastic models, namely, Neo-Hookean, Mooney-Rivlin and Yeoh models were considered [18, 19]:

Neo-Hookean: $\sigma=2\left((1+\varepsilon)^{2}-\frac{1}{(1+\varepsilon)}\right)\left(c_{10}\right)$,

Mooney-Rivlin: $\sigma=2\left((1+\varepsilon)^{2}-\frac{1}{(1+\varepsilon)}\right)\left(c_{10}+\frac{c_{01}}{(1+\varepsilon)}\right)$, 
Yeoh: $\sigma=2\left((1+\varepsilon)^{2}-\frac{1}{(1+\varepsilon)}\right)\left(c_{1}+2 c_{2}\left((1+\varepsilon)^{2}+\frac{2}{(1+\varepsilon)}-3\right)+3 c_{3}\left((1+\varepsilon)^{2}+\frac{2}{(1+\varepsilon)}-3\right)^{2}\right)$

where $\sigma$ and $\varepsilon$ denote stress and strain, respectively, and $c_{10}, c_{01}, c_{1}, c_{2}, c_{3}$ are unknown constants to be determined. The constants of the fit were extracted using least-squares analysis of the data in MATLAB. Further, in the limit $\varepsilon \rightarrow 0$, the elastic modulus, $E\left(=\frac{d \sigma}{d \varepsilon}\right)$ was evaluated as: $E=6 c_{10}$ for Neo-Hookean, $E=6\left(c_{10}+c_{01}\right)$ for Mooney-Rivlin, and $E=6 c_{1}$ for Yeoh models. Based on the resulting R-square value, the goodness of fit was determined to select the most appropriate model description.

\begin{tabular}{|c|c|c|c|c|c|c|}
\hline \multirow{2}{*}{$\begin{array}{c}\text { Crosshead } \\
\text { Speed } \\
(\mathrm{mm} / \mathrm{sec})\end{array}$} & \multicolumn{2}{|c|}{ Neo-Hookean } & \multicolumn{2}{|c|}{ Mooney-Rivlin } & \multicolumn{2}{|c|}{ Yeoh } \\
\hline & Constants & $\begin{array}{c}\text { Goodness of } \\
\text { fit }\end{array}$ & Constants & $\begin{array}{c}\text { Goodness of } \\
\text { fit }\end{array}$ & Constants & $\begin{array}{c}\text { Goodness of } \\
\text { fit }\end{array}$ \\
\hline 2.0 & $\mathrm{C}_{10}=6.169$ & 0.5317 & $\begin{array}{l}\mathrm{C}_{10}=-3.068, \\
\mathrm{C}_{01}=23.61\end{array}$ & 0.9954 & $\begin{array}{l}\mathrm{C}_{1}=13.7 \\
\mathrm{C}_{2}=-1.377 \\
\mathrm{C}_{3}=0.07379\end{array}$ & 0.9759 \\
\hline 0.2 & $\mathrm{C}_{10}=7.335$ & 0.6025 & $\begin{array}{l}\mathrm{C}_{10}=-4.993, \\
\mathrm{C}_{01}=24.25\end{array}$ & 0.9962 & $\begin{array}{l}\mathrm{C}_{1}=14.33 \\
\mathrm{C}_{2}=-2.739 \\
\mathrm{C}_{3}=0.2983\end{array}$ & 0.9852 \\
\hline 0.02 & $\mathrm{C}_{10}=8.314$ & 0.6650 & $\begin{array}{l}\mathrm{C}_{10}=-6.818, \\
\mathrm{C}_{01}=26.31\end{array}$ & 0.9957 & $\begin{array}{l}\mathrm{C}_{1}=15.47 \\
\mathrm{C}_{2}=-4.586 \\
\mathrm{C}_{3}=0.819\end{array}$ & 0.9888 \\
\hline
\end{tabular}

Table 1: Constants (units in $\mathrm{N} / \mathrm{m}^{2}$ ) determined and the quality of fit obtained from least-squares analysis of tensile test data in Fig. 3.

Table 1 summarizes information gathered through least-squares analysis of stress-strain data in Fig. 3 for all the three crosshead speeds and hyperelastic models in Eq. (1). A graphical representation of the same for one case shown in Fig. 4(c) illustrates the resulting match between experiments and analysis over the entire strain range. Out of the three models, Mooney-Rivlin was the one that had the best fit of the data. Further, the Mooney-Rivlin model is among the most commonly used model in the literature $[20,21]$ for describing the mechanical behavior of 
biological tissues. The elastic modulus thus obtained for each loading rate is shown in Table 2. The elastic modulus varies only modestly, by $\sim 20 \%$, between the low and high crosshead speeds considered. Further, the values fall into the wide range of elastic properties reported in the literature for biological tissues.

\begin{tabular}{|c|c|c|c|c|c|}
\hline $\begin{array}{c}\text { Crosshead } \\
\text { Speed } \\
(\mathbf{m m} / \mathbf{s e c})\end{array}$ & $\begin{array}{c}\text { Elastic } \\
\text { Modulus, } \boldsymbol{E} \\
\mathbf{( k P a )}\end{array}$ & $\begin{array}{c}\text { Poisson's } \\
\text { Ratio, } \boldsymbol{v}\end{array}$ & $\begin{array}{c}\text { Ultimate } \\
\text { Stress, } \mathbf{k P a}\end{array}$ & $\begin{array}{c}\text { Failure } \\
\text { Strain }\end{array}$ & $\begin{array}{c}\text { Strain Rate, } \\
\dot{\varepsilon}\left(\mathbf{s e c}^{-1}\right)\end{array}$ \\
\hline 2.0 & $125.4 \pm 4.08$ & $0.46 \pm 0.011$ & $87.16 \pm 1.63$ & $1.97 \pm 0.05$ & 0.04 \\
\hline 0.2 & $118.4 \pm 2.80$ & $0.47 \pm 0.006$ & $54.48 \pm 1.01$ & $1.25 \pm 0.11$ & 0.004 \\
\hline 0.02 & $111.4 \pm 3.17$ & $0.46 \pm 0.013$ & $42.69 \pm 2.81$ & $0.99 \pm 0.01$ & 0.0004 \\
\hline
\end{tabular}

Table 2: Elastic modulus, Poisson's ratio, ultimate stress and failure strain dependence on crosshead speed in tension test.

During tension tests, transverse strains were also obtained from DIC along with the axial counterparts. The engineering axial and transverse strain responses for different crosshead speeds are shown in Fig. 5. The initial region was used in each of the above graphs to estimate the Poisson's ratio of the gel using a linear regression analysis. The ultimate stress and failure strain were also recorded for different experiments, and are shown in Table 1. Both the values increased with an increase in crosshead speed. The increase in the ultimate stress was expected; however, the same in failure strain is an interesting behavior of this polymer gel. For example, relative to the $0.02 \mathrm{~mm} / \mathrm{sec}$ crosshead speed case, the sample loaded at $2 \mathrm{~mm} / \mathrm{sec}$ showed approximately $100 \%$ increase in the failure strain.

\section{Elastic Response in Shear}

Simple shear tests were conducted to determine the shear modulus of the polymer gel. The effect of strain rate on the shear modulus was quantified. The experimentally evaluated shear moduli were compared with those anticipated from tension tests.

A photograph of the experimental setup used is shown in Fig. 6. Rectangular gel blocks glued to two L-shaped polycarbonate holders were pulled axially using tension grips. The shear samples were made from void-free rectangular gel sheets of $12.5 \mathrm{~mm}$ thickness. A hotwire cutter 
(temperature range of $100^{\circ} \mathrm{C}-200^{\circ} \mathrm{C}$ ) was used to cut rectangular blocks of $25 \mathrm{~mm} \times 12.5 \mathrm{~mm} \times$ $12.5 \mathrm{~mm}$ dimensions. Loctite 401 acrylic adhesive was used to create a bond between the sample and the L-shaped polycarbonate holders. The red vertical lines in the figure denote the glued portion of the sample. The applied tensile force was transmitted to the sample as a shear force acting on the two $25 \mathrm{~mm} \times 12.5 \mathrm{~mm}$ faces of the gel sample. The shear tests were performed again at three different crosshead speeds of $0.02,0.2$ and $2 \mathrm{~mm} / \mathrm{sec}$, the same as for the tension tests. The tests were conducted only until the interface between the holder and the sample started to debond and the gel samples did not fail in shear.

\begin{tabular}{|c|c|c|c|}
\hline $\begin{array}{c}\text { Crosshead } \\
\text { Speed } \\
(\mathbf{m m} / \mathbf{s e c})\end{array}$ & $\begin{array}{c}\text { Shear } \\
\text { Modulus } \\
\text { from Shear } \\
\text { Tests, } \boldsymbol{G} \\
\text { (kPa) }\end{array}$ & $\begin{array}{c}\text { Shear } \\
\text { Modulus } \\
\text { from Tension } \\
\text { Tests, } \boldsymbol{G} \\
\left(=\frac{E}{3}\right) \mathbf{k P a}\end{array}$ & $\begin{array}{c}\text { Strain Rate, } \\
\dot{\varepsilon} \mathbf{s e c}^{-1}\end{array}$ \\
\hline 2.0 & $41.9 \pm 1.5$ & $41.8 \pm 1.8$ & 0.04 \\
\hline 0.2 & $39.6 \pm 1.1$ & $39.5 \pm 1.2$ & 0.004 \\
\hline 0.02 & $36.7 \pm 0.9$ & $37.1 \pm 1.4$ & 0.0004 \\
\hline
\end{tabular}

Table 3: Comparison of shear modulus values from shear tests and tension tests at different crosshead speeds.

The load data obtained from the testing machine and cross-sectional area of the sample on which the shear force acted were used to evaluate the shear stress. The dimensions of the gel block and the vertical displacement of the crosshead were used to calculate the shear strain. The resulting shear stress-shear strain responses are shown in Fig. 7. As in tension tests, a loading rate effect was evident. A monotonic stiffer response was seen with increasing crosshead speed. These tests were also highly repeatable and the details are omitted here for brevity.

As in tension tests, assuming hyperelastic material response and Mooney-Rivlin characteristics between shear stress and shear strain, the shear modulus was evaluated [18, 19] using least-squares analysis described earlier, and the results are shown in Table 3. Good 
agreement between those measured from the shear tests and the tensile counterparts are evident and they independently validate the measurements made for the polymer gel.

\section{Elasto-Optical Constant}

The specimen geometry adopted for extracting the elasto-optical constant of the polymer gel was a disk under diametrical compression. The loading configuration was inspired by the stress-optical constant evaluation approach commonly used in 2D photoelasticity [23] practice. The disk specimens for these experiments had to be prepared, again using non-traditional approaches, as detailed next: First, rectangular gel sheets of $12.5 \mathrm{~mm}$ thickness devoid of air bubbles and good surface finish were prepared. A hollow metal tube with an inner diameter of 50 mm was machined to make the periphery of one of the ends sharp to punch out a circular disk sample from the sheet. Only the outer surface was machined to achieve the sharp edge while the inner surface of the punch was straight. The lubricated punch was first heated to $80^{\circ} \mathrm{C}$ in an oven and then pressed into the gel sheet, resting flat on a polycarbonate substrate, at right angles. Figure 8 shows a photograph of the resulting circular gel disk of diameter $50 \mathrm{~mm}$.

A schematic representation of the optical setup used for evaluating the elasto-optical constant for the gel is shown in Fig. 9. A full-field optical technique called Digital Gradient Sensing (DGS) was used to perform these measurements. The circular disk specimen was $50 \mathrm{~mm}$ in diameter and $12.5 \mathrm{~mm}$ thickness. The specimen was subjected to diametral compression in a testing machine at three different crosshead speeds $0.02,0.2$ and $2 \mathrm{~mm} / \mathrm{sec}$, consistent with the mechanical tests reported earlier. A planar target plate decorated with random black and white speckles was placed at a distance $\Delta=32 \mathrm{~mm}$ away from the mid-plane of the specimen.

\section{Digital Gradient Sensing Method}

The working principle of transmission-mode DGS method can be explained using Fig. 9. A random speckle pattern (created using alternate mists of black and white spray paint on a planar substrate) on the target plate was first recorded through a transparent specimen - the circular disk of uniform initial thickness in this work - as a reference image in 'no-load' condition. Ordinary white light was used to illuminate the target uniformly. In this condition, a generic point $\mathrm{P}$ on the target plate corresponds to point $\mathrm{O}$ on the specimen plane. The specimen was then subjected to 
mechanical load, affecting the refractive index and thickness of the specimen according to the state of stress at a point of interest in the field. As a result, the light rays propagating through the specimen deviate from their initial path, and is referred to as the elasto-optical effect. In the deformed state of the specimen, another image of the speckles on the target was recorded through the gel disk. That is, during the second recording the point $\mathrm{P}$ appears to have displaced to, say, $Q$ on the target plate when recorded through $\mathrm{O}$ on the specimen plane. By correlating the two speckle images from the undeformed and deformed states of the specimen, the local speckle displacements $\delta_{x: y}$ were evaluated. Subsequently, the angular deflections of light rays $\phi_{x: y}$ were related to the in-plane stress gradients [22] as:

$$
\phi_{x: y} \approx \frac{\delta_{x: y}}{\Delta}=C_{\sigma} B \frac{\partial\left(\sigma_{x x}+\sigma_{y y}\right)}{\partial(x: y)}
$$

where $C_{\sigma}$ is the elasto-optical constant of the specimen material, $B$ is its initial thickness, $\Delta$ is the distance between the specimen and target plate. Assuming a pin-hole camera mapping function, coordinates of the target can be related to those of the specimen.

During these experiments, a Point Grey digital camera (Grasshopper3 GS3-U3-41C6M) fitted with 18-108 mm macro zoom lens was used to record speckle images. The camera was situated at a distance of approximately $600 \mathrm{~mm}$ from the specimen. The speckle pattern on the target plate was illuminated using two cool LED lamps to mitigate heating of the sample during the experiment. The camera was focused on speckles through the transparent gel disk and a reference image (undeformed image) was recorded before the sample was loaded. To minimize friction, the disk was compressed by two lubricated polycarbonate blocks held in the grips of the testing machine. As shown in Fig. 10, when the load increased, speckle images corresponding to different deformed states of the sample were recorded at regular time intervals at 1-10 frames/sec depending on the crosshead speed. The images recorded at different load levels were individually correlated with that corresponding to the reference state ${ }^{1}$ using the image analysis software ARAMIS. An array of in-plane speckle displacement components on the target plane (and hence the specimen plane) was evaluated and converted into local angular deflections of light rays $\phi_{x}$

\footnotetext{
${ }^{1}$ It should also be noted that speckles photographed through the disk appear different at the top and bottom contact locations. This is attributed to the compliant nature of the gel and contact conditions due to specimen fabrication steps. Hence, the reference image may not correspond to a zero state of stress. Accordingly, speckle correlation between the reference and loaded states should be viewed as between two incremental/neighboring deformed states.
} 
and $\phi_{y}$. A facet/sub-image size of $75 \times 75$ pixels and facet overlap of 50 pixels (scale factor $=$ $0.026 \mathrm{~mm} /$ pixel) resulting in a $39 \times 39$ data array was used to achieve correlation in the entire region of interest. A relatively large facet size [17] was needed due to large deformations suffered by the specimen, particularly near the loading points.

Figure 11 shows the resulting orthogonal angular deflection contours of $\phi_{x}$ and $\phi_{y}$ for an imposed displacement of $1.5 \mathrm{~mm}$ at three crosshead speeds $0.02,0.2$ and $2 \mathrm{~mm}$ per sec, respectively. The contours near the two loading points show a high concentration of contours with significant $3 \mathrm{D}$ effects. The differences in the contour shapes at the top and the bottom despite symmetric loading are attributed to differences in the contact conditions during experiments and edge effects associated with specimen preparation anomalies and image analysis. However, away from these points of stress concentration, the deformations are affected less by $3 \mathrm{D}$ effects and the optical data can be readily extracted in the central region of the disk, as depicted by the (red) dotted line in the $0.2 \mathrm{~mm} / \mathrm{sec}$ case in Fig. 11 (middle column). Accordingly, the experimental data along the $x$-and $y$-axes of the disk were extracted and plotted in Fig. 14 away from the loading points as (red) solid symbols for a load level of $-0.98 \mathrm{~N}$ for all three crosshead speeds studied.

The analytical expressions for normal stresses in a linear elastic disk under diametral compression [24] are,

$$
\begin{aligned}
& \sigma_{x x}=-\frac{2 F}{\pi}\left[\frac{(R-y) x^{2}}{r_{1}^{4}}+\frac{(R+y) x^{2}}{r_{2}^{4}}-\frac{1}{2 R}\right] \\
& \sigma_{y y}=-\frac{2 F}{\pi}\left[\frac{(R-y)^{3}}{r_{1}^{4}}+\frac{(R+y)^{3}}{r_{2}^{4}}-\frac{1}{2 R}\right]
\end{aligned}
$$

where $r_{1,2}=\sqrt{x^{2}+(R \mp y)^{2}}, F$ is the applied load per unit thickness, $R$ is the radius of the circular disk, $x$ and $y$ are the Cartesian coordinates, as shown in Fig. 9. The expressions for angular deflections $\phi_{x}$ and $\phi_{y}$ can be obtained from Eq. (2) by considering the derivatives of $\left(\sigma_{x x}+\sigma_{y y}\right)$ with respect to the $x$ - and $y$-coordinates: 


$$
\begin{aligned}
& \phi_{x}=C_{\sigma} B\left[\left(\frac{16 F R^{3} x}{\pi\left(R^{2}+x^{2}\right)^{3}}\right)-\frac{2 F}{\pi}\left(\frac{4 R x}{\left(R^{2}+x^{2}\right)^{2}}-\frac{8 R x^{3}}{\left(R^{2}+x^{2}\right)^{3}}\right)\right] \\
& \phi_{y}=C_{\sigma} B\left[\frac{-2 F}{\pi}\left(\frac{2(2 R-2 y)}{(R-y)^{3}}+\frac{3}{(R+y)^{2}}-\frac{2(2 R+2 y)}{(R+y)^{3}}-\frac{3}{(R-y)^{2}}\right)\right]
\end{aligned}
$$

The optical data in the region $-0.5 \leq \frac{x ; y}{R} \leq 0.5$ from $\phi_{x}$ and $\phi_{y}$, respectively, were analyzed using least-squares analysis in conjunction with Eqs. (4) and (5) since all parameters except the elasto-optical constant $C_{\sigma}$ are known. Obtained values of $C_{\sigma}$ are listed in Table 4 . These represent results from both the $x$ - and $y$-directions at multiple load levels averaged into a single value. Evidently, the $C_{\sigma}$ values are negative and affected by the crosshead speed. Further, the magnitude increases as the crosshead speed decreases.

\begin{tabular}{|c|c|c|}
\hline $\begin{array}{c}\text { Crosshead } \\
\text { speed } \\
(\mathbf{m m} / \mathbf{s e c})\end{array}$ & $\begin{array}{c}\text { Elasto-Optic } \\
\text { Constant } \boldsymbol{C}_{\boldsymbol{\sigma}} \\
\left(\mathbf{m m}^{\mathbf{2}} / \mathbf{N}\right)\end{array}$ & $\begin{array}{c}\text { Strain Rate, } \\
\dot{\varepsilon} \mathbf{~ s e c}^{-1}\end{array}$ \\
\hline 2.0 & $-1.18 \pm 0.056$ & 0.04 \\
\hline 0.2 & $-1.28 \pm 0.075$ & 0.004 \\
\hline 0.02 & $-1.47 \pm 0.053$ & 0.0004 \\
\hline
\end{tabular}

Table 4: Dependence of elasto-optic constant on strain rate.

As noted earlier, the elasto-optical constant represents a combined effect of refraction index $(n)$ change $(\delta n)$ and Poisson effects due to stresses and is given by [22],

$$
C_{\sigma}=D_{1}-\frac{v}{E}(n-1)
$$

and

$$
\delta n(x, y) \approx D_{1}\left(\sigma_{x x}+\sigma_{y y}\right)
$$

where $D_{1}$ is a stress-optic constant of the material [23]. From Eq. (7), the sign of $D_{1}$ can be understood. When the material is locally under tension (compression), its density decreases (increases) and, as a result, the refractive index also decreases (increases). Hence, in both these 
cases, the sign of the stress-optic constant will be negative. From Eq. (6), as the elastic modulus is directly proportional to the crosshead speed, the elasto-optic constant for the gel is inversely proportional to the crosshead speed. This can be observed from Table 4.

Using the $C_{\sigma}$ values from Table 4 , the variation of angular deflections along the $x$ - and $y$ axes of the disk is plotted in Fig. 12 as a (black) solid line. The agreement between the measurements and the fit are generally good in each of the cases. Figure 13 shows comparison between measured and analytical quantities as contours in the entire field for a load of $F=-0.98$ N. Evidently, the overall deformation patterns, particularly the ones away from the loading points in the central regions of the disk, compare well with each other.

\section{Conclusions}

The feasibility of using a polymer gel was explored to aid future investigations using this material as a tissue surrogate by undertaking its mechanical and optical characterization. Mechanical behavior under tension and shear was carried out first. In light of the challenges associated with the ultralow stiffness of the material, many non-traditional approaches had to be adopted for preparing the material/samples, gripping the samples and measuring deformations to evaluate both elastic and failure characteristics. Two optical methods, 2D digital image correlation and transmission-mode digital gradient sensing, based on spatial correlation of random speckle patterns, were extended in this work to soft materials. The former method was used to measure both axial and transverse strains simultaneously. By performing tests at three different strain rates, the rate dependent response of the gel was assessed. The hyperelastic Money-Rivlin material model captured the measured responses well. The tensile elastic modulus showed a modest (approx. 12\%) increase when the strain rate was increased from 0.0004 to 0.04 . The Poisson's ratio was in the range of 0.47-0.48, consistent with expected incompressible behavior predicted by a value of 0.5 . However, the increase in the ultimate stress and failure strain was nearly $100 \%$ over the same strain rates. Further, the increase of failure strain with strain rate was unexpected but consistent with other reports on hydrogels found in the literature. The shear tests were used to extract shear modulus of this gel at three strain rates, and was independently verified using tensile modulus and Poisson's ratio evaluated from tension tests. 
The optical transparency of the gel made it suitable for visualization and quantification of mechanical fields. Specifically, the potential of the full-field optical method, namely the digital gradient sensing technique, was explored by evaluating the elasto-optical constant for the gel at different strain rates. Suitability of a disk under diametral compression geometry for this purpose was demonstrated by extracting two orthogonal stress gradient data sets in the central region of the disk where $3 \mathrm{D}$ deformations are minimum. The measurements indicate that the magnitude of the elasto-optical constant dropped approximately $20 \%$ as the strain rate increased from 0.0004 to 0.04 , consistent with the changes expected for refractive index and the elastic modulus measurements.

\section{Acknowledgements}

Partial support of this research through grants CMMI-1232821 from the National Science Foundation and W911NF-12-1-0317 from the U.S. Army Research Office is gratefully acknowledged.

\section{References}

1. Peterson, B. 'Ballistic Gelatin Lethality Performance of 0.375-in Ball Bearings and MAAWS 401B Flechettes.' Army Research Laboratory Technical Report. ARL-TR-4153, (2007).

2. Maiden, N. "Historical overview of wound ballistics research." Forensic Science, Medicine, and Pathology, 5.2 (2009): 85-89.

3. MacPherson, D. Bullet Penetration: Modeling the Dynamics and the Incapacitation Resulting from Wound Trauma. Ballistic Publications, El Segundo, California, USA, (2005).

4. Juliano, T. F., Foster, A. M., Drzal, P. L., Weerasooriya, T., Moy, P., VanLandingham, M. R., "Multiscale mechanical characterization of biomimetic physically associating gels." Journal of Materials Research, 21.08 (2006): 2084-2092.

5. Wen, Y, Xu, C., Wang, S. and Batra, R.C. "Analysis of behind the armor ballistic trauma." Journal of the Mechanical Behavior of Biomedical Materials 45: 11-21 (2015).

6. Sallaway, L., Magee, S., Shi, J., Lehmann, O., Quivira, F., Tgavalekos, K., Brooks, D.H., Muftu, S., Meleis, W., Moore, R.H. and Kopans, D. "Detecting Solid Masses in Phantom Breast Using Mechanical Indentation." Experimental Mechanics, 54.6: 935-942 (2014). 
7. Nicholas, N. C., and J. R. Welsch. Institute for Non-Lethal Defense Technologies Report: Ballistic Gelatin. Pennsylvania State University, University Park Applied Research Lab, (2004).

8. Moy, P, T. Weerasooriya, and C. A. Gunnarsson. "Tensile deformation of ballistic gelatin as a function of loading rate." Proceedings of the XIth International Congress and Exposition, Society for Experimental Mechanics, (2008).

9. Subhash, G., Liu, Q., Moore, D. F., Ifju, P. G., and Haile, M. A., "Concentration dependence of tensile behavior in agarose gel using digital image correlation." Experimental Mechanics, 51(2), 255-262 (2011).

10. Tomlinson, R. A. and Taylor, Z. A., "Photoelastic materials and methods for tissue biomechanics applications." Optical Engineering 54.8, No. 081208, (2015).

11. Nguyen, C. T., and Vu-Khanh, T., Mechanics and mechanisms of puncture by medical needles. Procedia Engineering, 1(1), 139-142 (2009).

12. Okamura, A. M., Simone, C., and Leary, M. "Force modeling for needle insertion into soft tissue." IEEE Transactions on Biomedical Engineering, 51.10: 1707-1716 (2004).

13. Jiang, S., Li, P., Yu, Y., Liu, J. and Yang, Z. "Experimental study of needle-tissue interaction forces: effect of needle geometries, insertion methods and tissue characteristics." Journal of Biomechanics 47.13: 3344-3353 (2014).

14. DiMaio, S. P., and Salcudean, S. E. "Needle insertion modeling and simulation." Robotics and Automation, IEEE Transactions on 19.5: 864-875 (2003).

15. Griffiths, P. R., and De Haseth, J. A., Fourier Transform Infrared Spectrometry. Vol. 171. John Wiley \& Sons, (2007).

16. Stuart, B. Infrared Spectroscopy. John Wiley \& Sons, Inc., (2005).

17. Pickerd, V. Optimization and Validation of the ARAMIS Digital Image Correlation System for Use in Large-scale High-strain-rate Events. No. DSTO-TN-1203. Defense Science and Technology Organization Victoria (Australia) Maritime Platforms Division, (2013).

18. Ogden, R. W., Nonlinear Elastic Deformations, Dover, (1998).

19. Macosko, C. W. Rheology: Principles, Measurement and Applications, VCH Publishers, (1994). 
20. Mendis, K. K., Stalnaker, R. L. and Advani, S. H. "A constitutive relationship for large deformation finite element modeling of brain tissue." Journal of Biomechanical Engineering 117.3: 279-285 (1995).

21. Lally, C., Reid, A. J., and Prendergast, P. J. "Elastic behavior of porcine coronary artery tissue under uniaxial and equibiaxial tension." Annals of Biomedical Engineering 32.10: 1355-1364 (2004).

22. Periasamy, C., and Tippur, H. V. "A Full-Field Digital Gradient Sensing Method for Evaluating Stress Gradients in Transparent Solids.” Applied Optics, Vol. 51, No. 12, pp 2088-2097 (2012).

23. Dally, J. W. and Riley W. F., Experimental Stress Analysis, College House Enterprises, (2005).

24. Sadd, M. H., Elasticity - Theory, Applications and Numerics, Academic Press, (2009). 


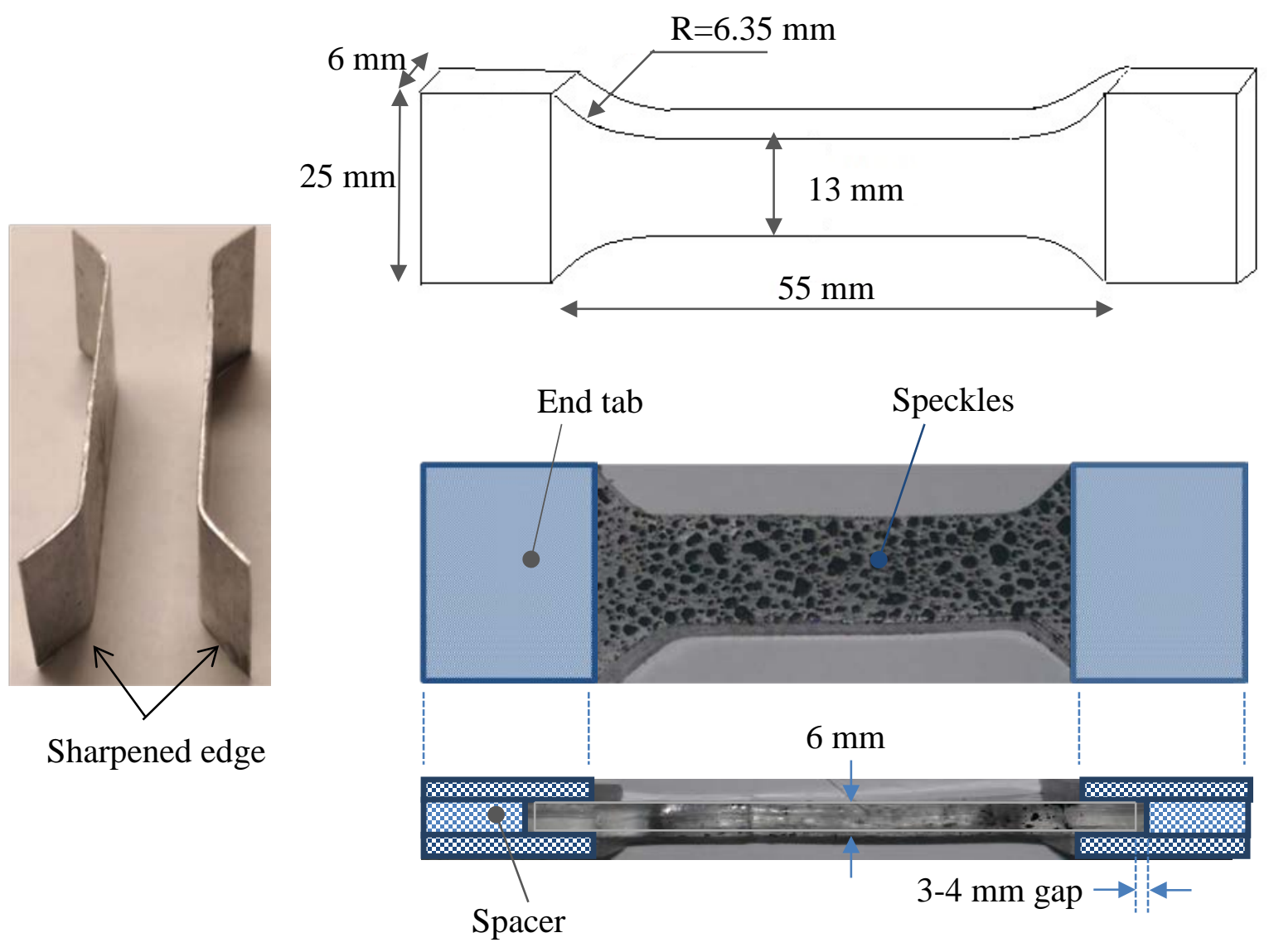

Figure 1: Aluminum foils used to cut tensile test samples (left), schematic of tensile test sample (top), successful configuration of tensile test dog-bone specimen with polycarbonate end tabs and spacers (bottom). 


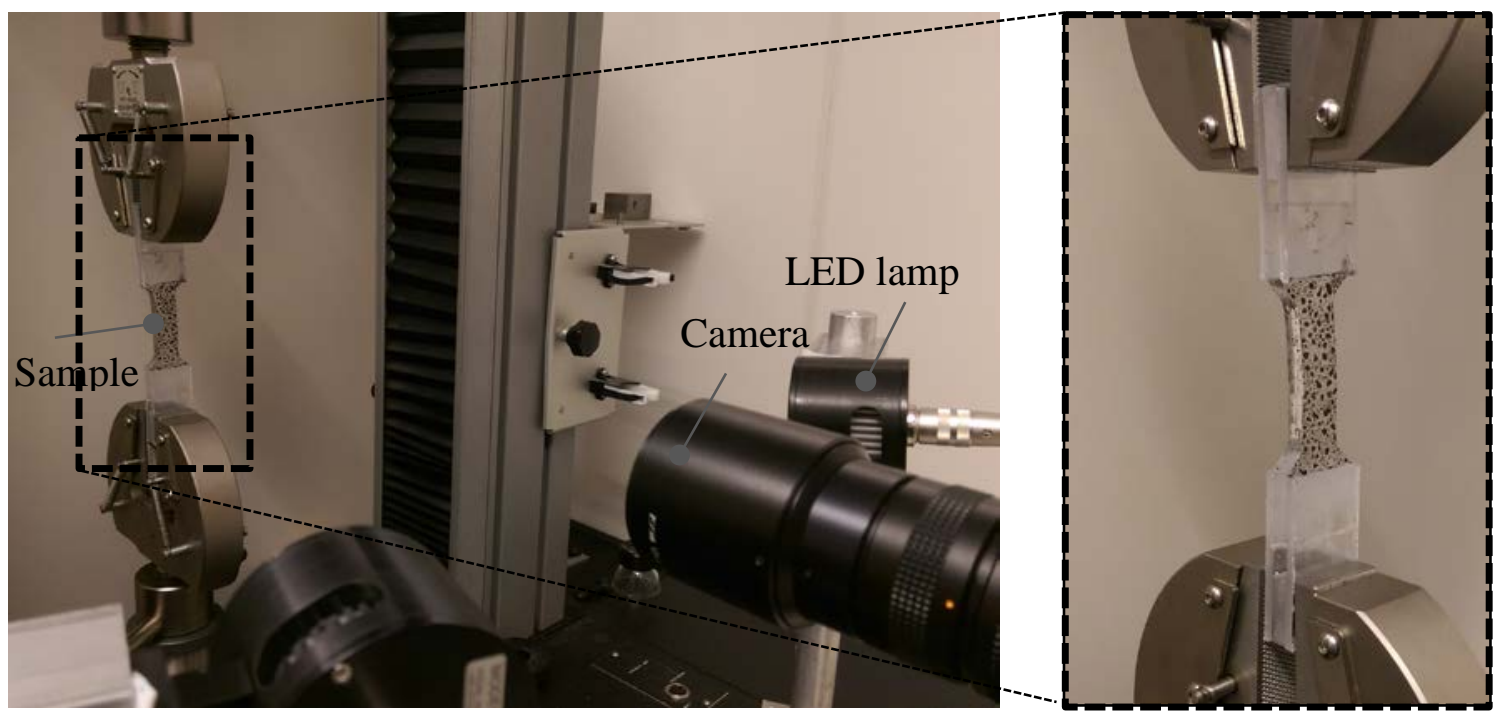

Figure 2: Photograph of the experimental setup used for tension test on ballistic polymer gel (left), the close-up (right) shows tensile test sample with speckle pattern. 


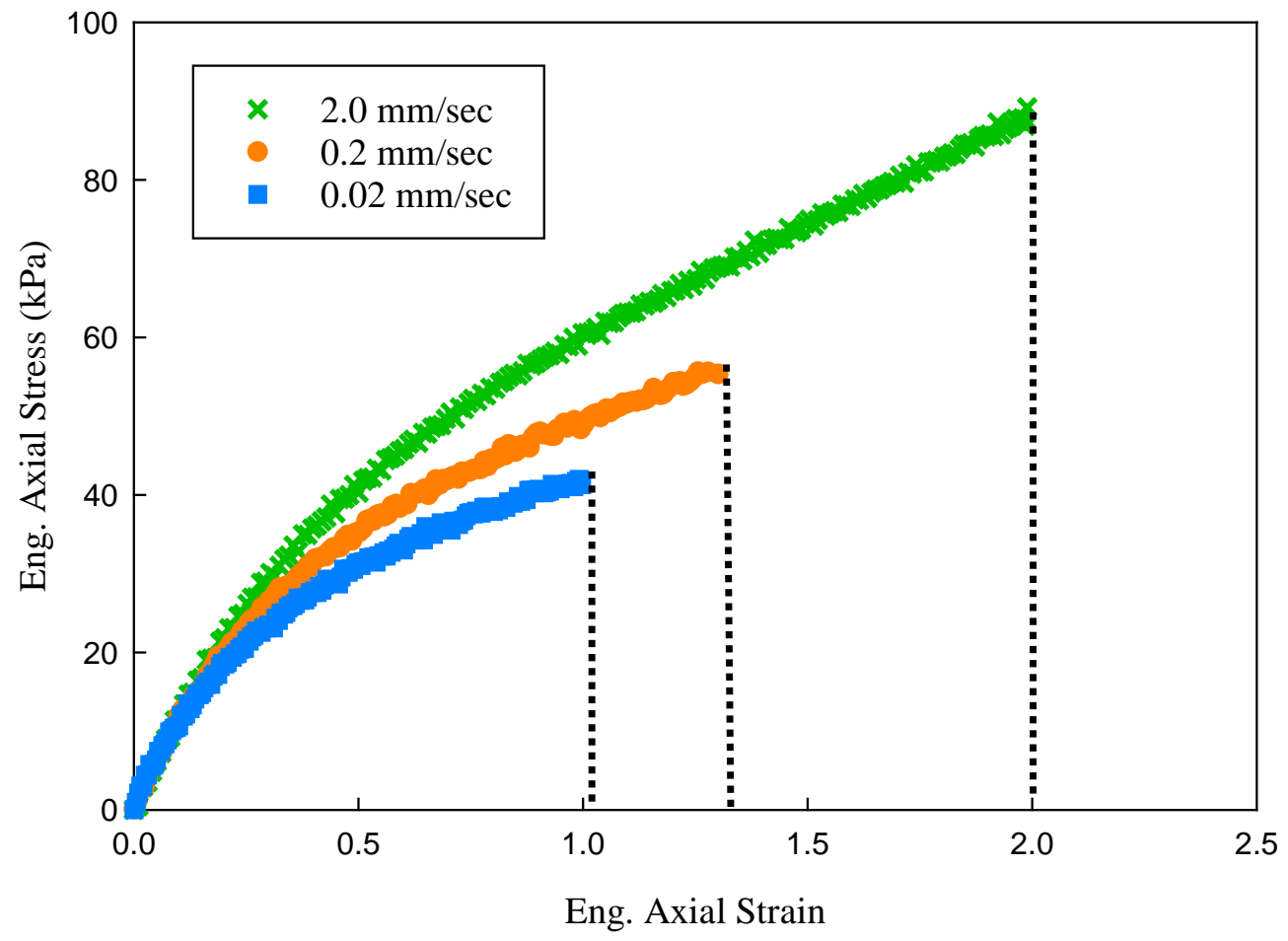

Figure 3: Tensile stress-strain response of polymer gel at three different crosshead speeds. (Dotted lines represented failure strain.) 
(a)

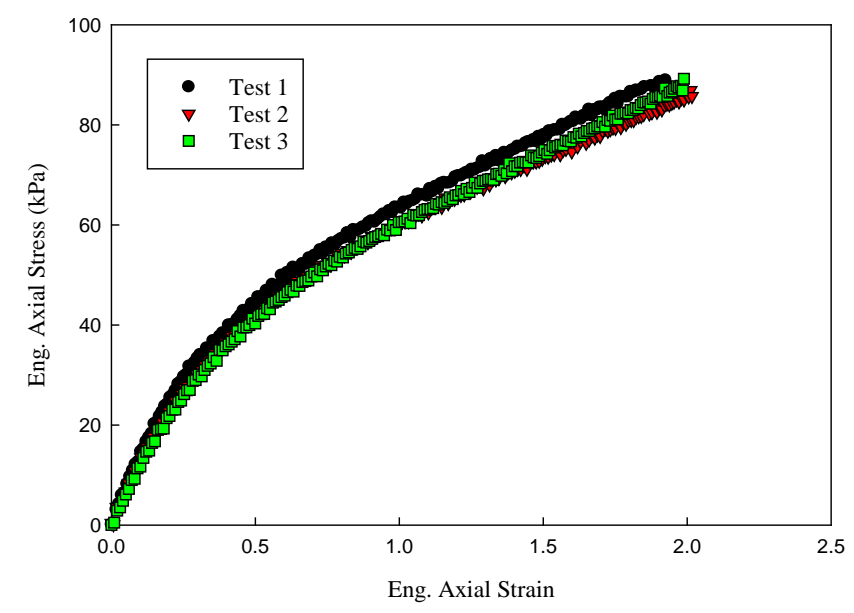

(b)

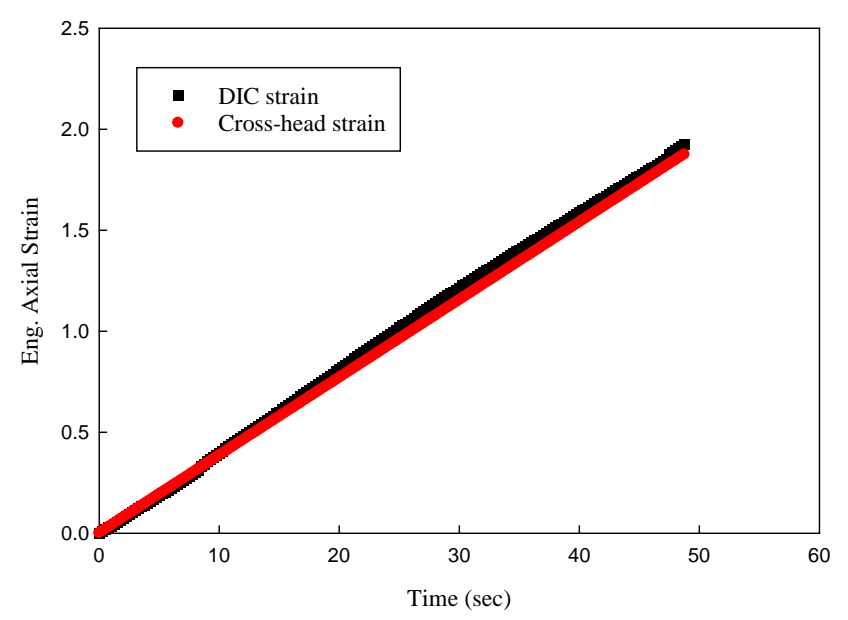

(c)

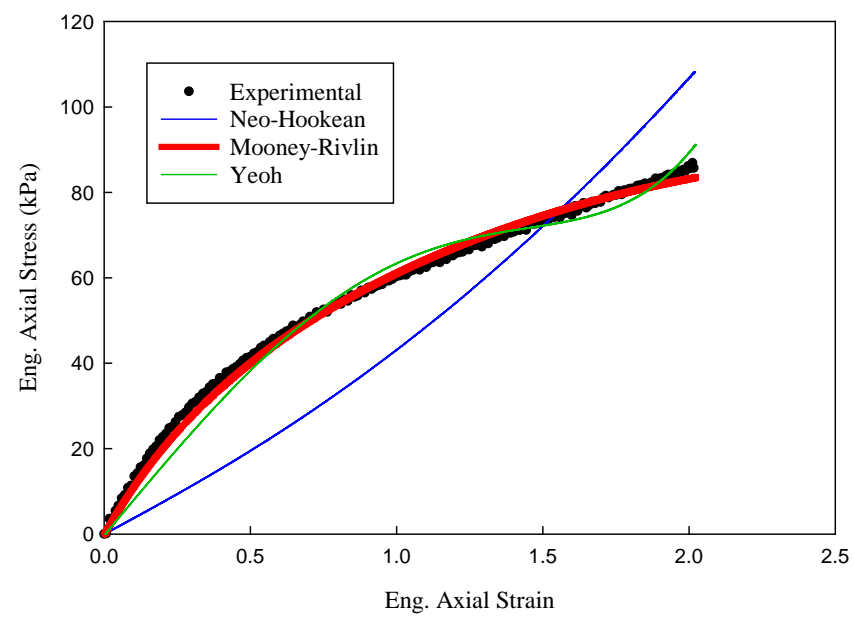

Figure 4: (a) Engineering stress-strain responses to check repeatability of tension tests, (b) Comparison of strains obtained from cross-head displacement and Digital Image Correlation (DIC), (c) Comparison of stress-strain responses from experiment and three different hyperelastic models. 


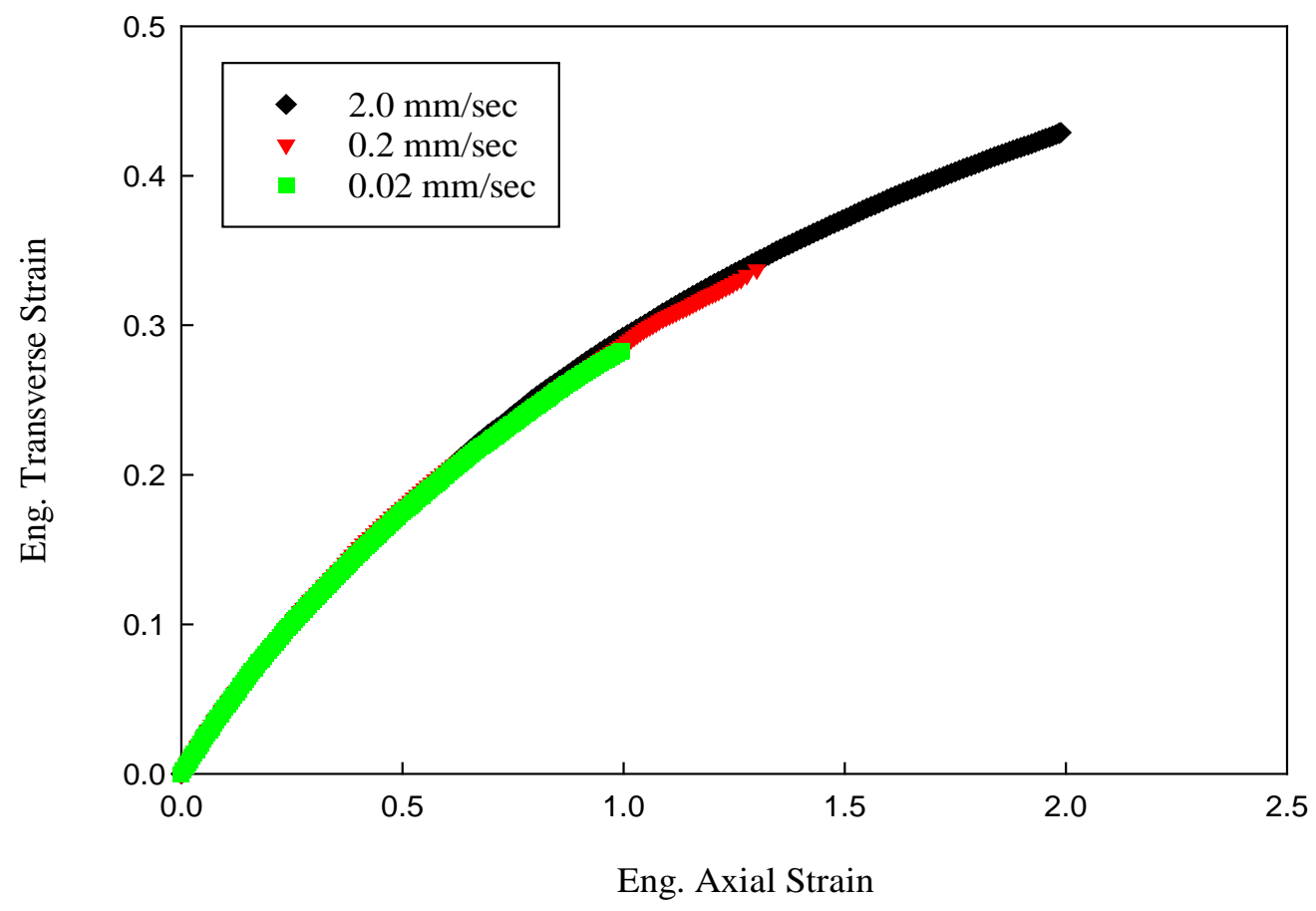

Figure 5: Engineering transverse strain vs axial strain response at different crosshead speeds. 

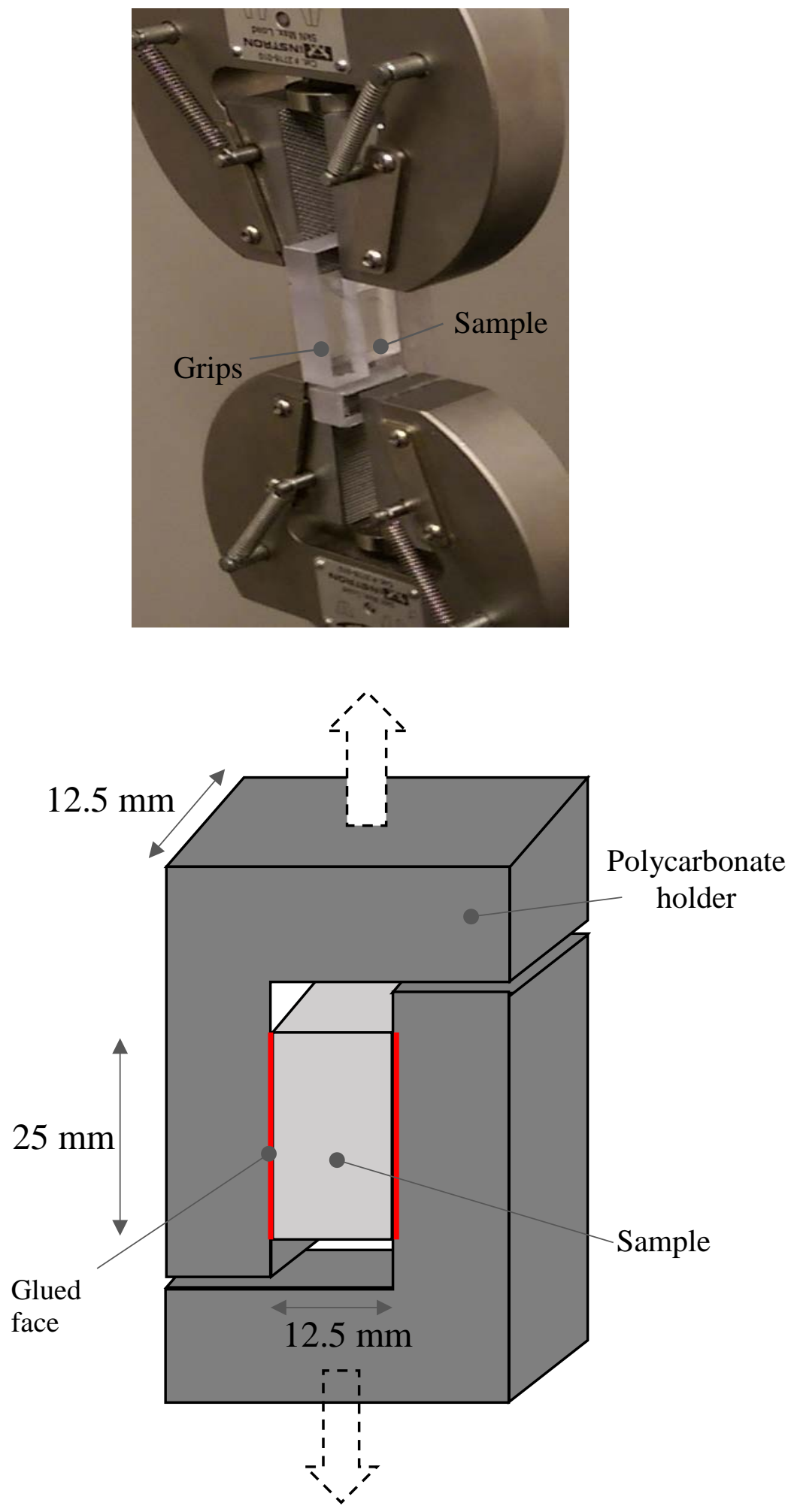

Figure 6: Shear test sample gripped using standard testing machine grips (top), schematic of the sample holder and specimen (bottom). 


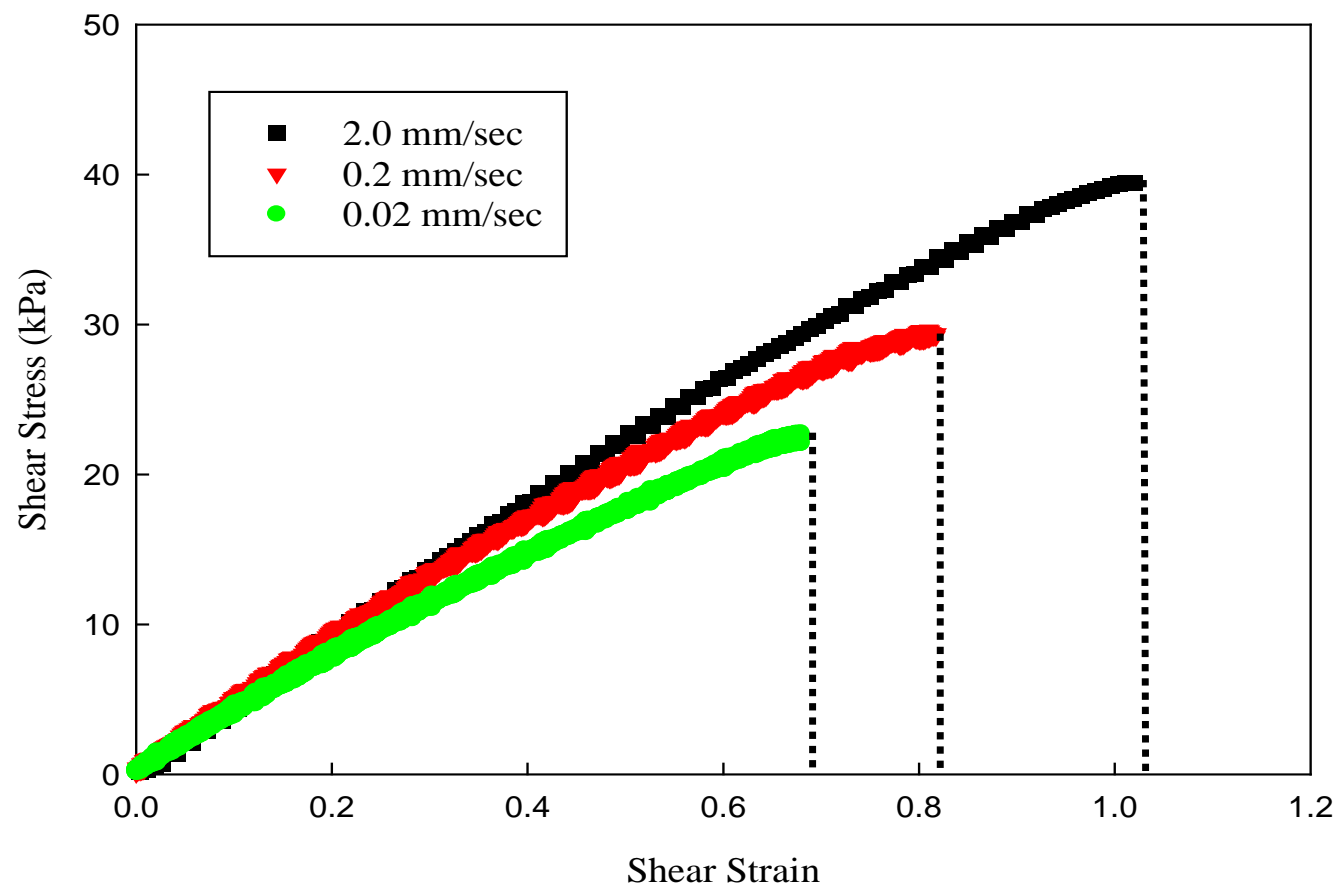

Figure 7: Effect of crosshead speed on shear stress-shear strain response of the gel. (The dotted lines indicate failure of the holder-sample adhesive and not the sample failure.) 

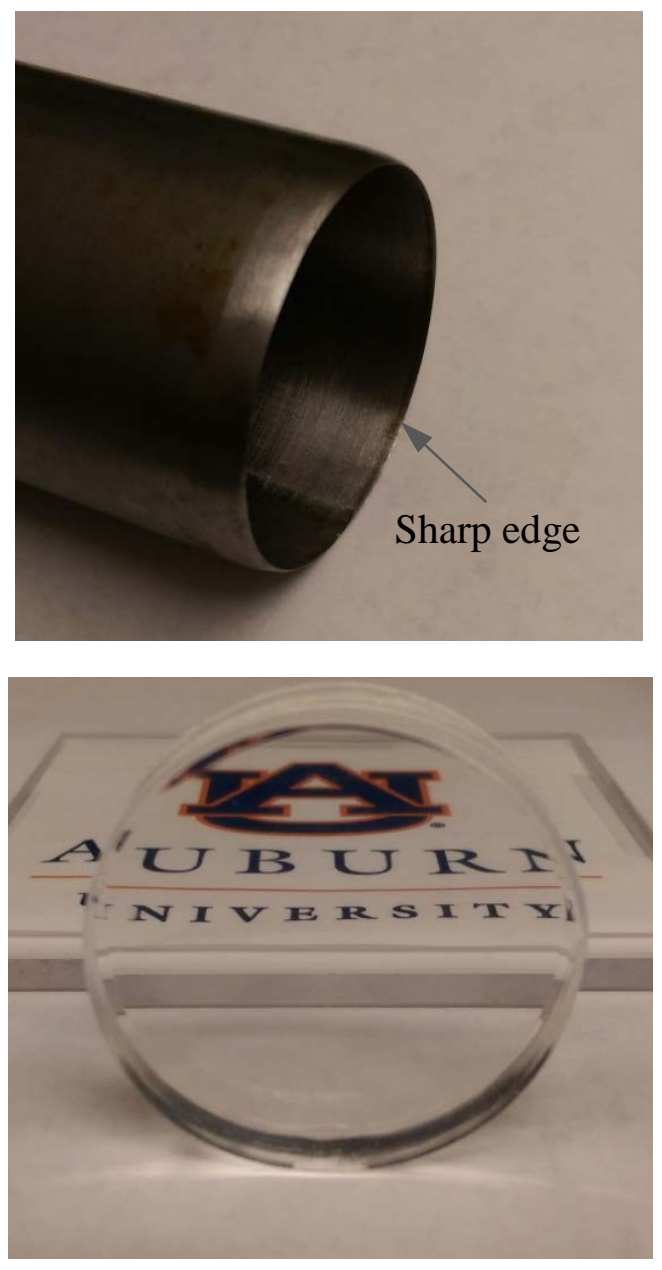

Figure 8: Hollow metal tube (top) to punch out circular disk specimen and the resulting transparent disk shaped gel specimen (bottom) 


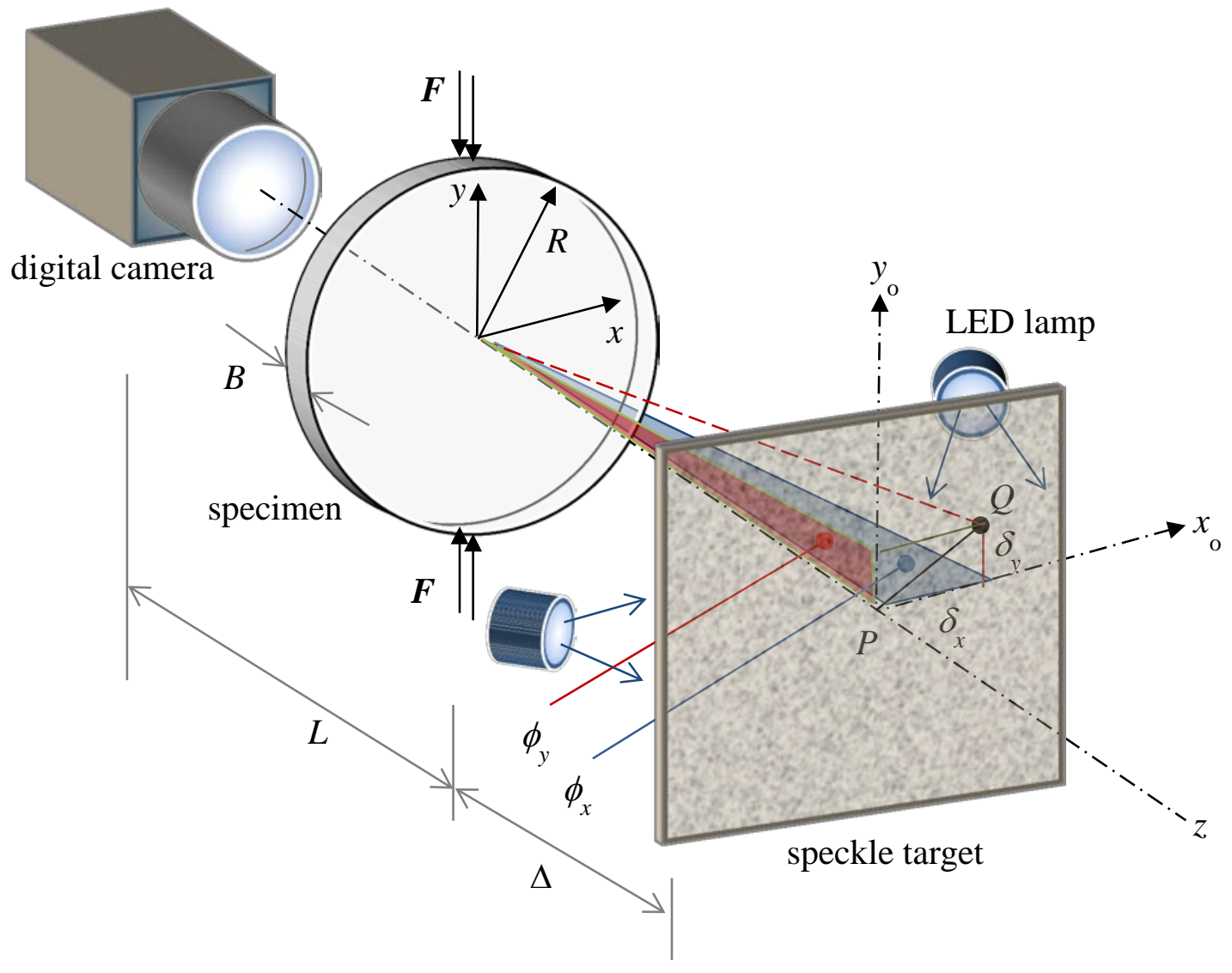

Figure 9: Schematic of the experimental setup used for studying polymer gel disk under diametrical compression using Digital Gradient Sensing (DGS) method. 

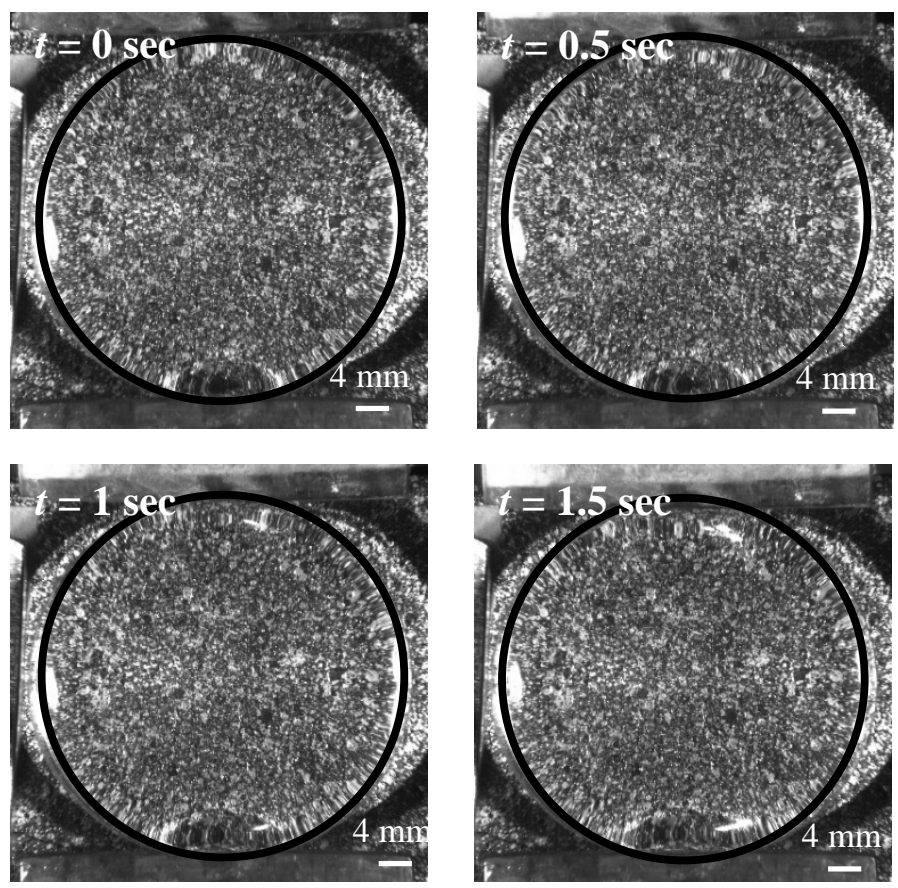

Figure 10: Speckle images taken at different time intervals during the experiment.
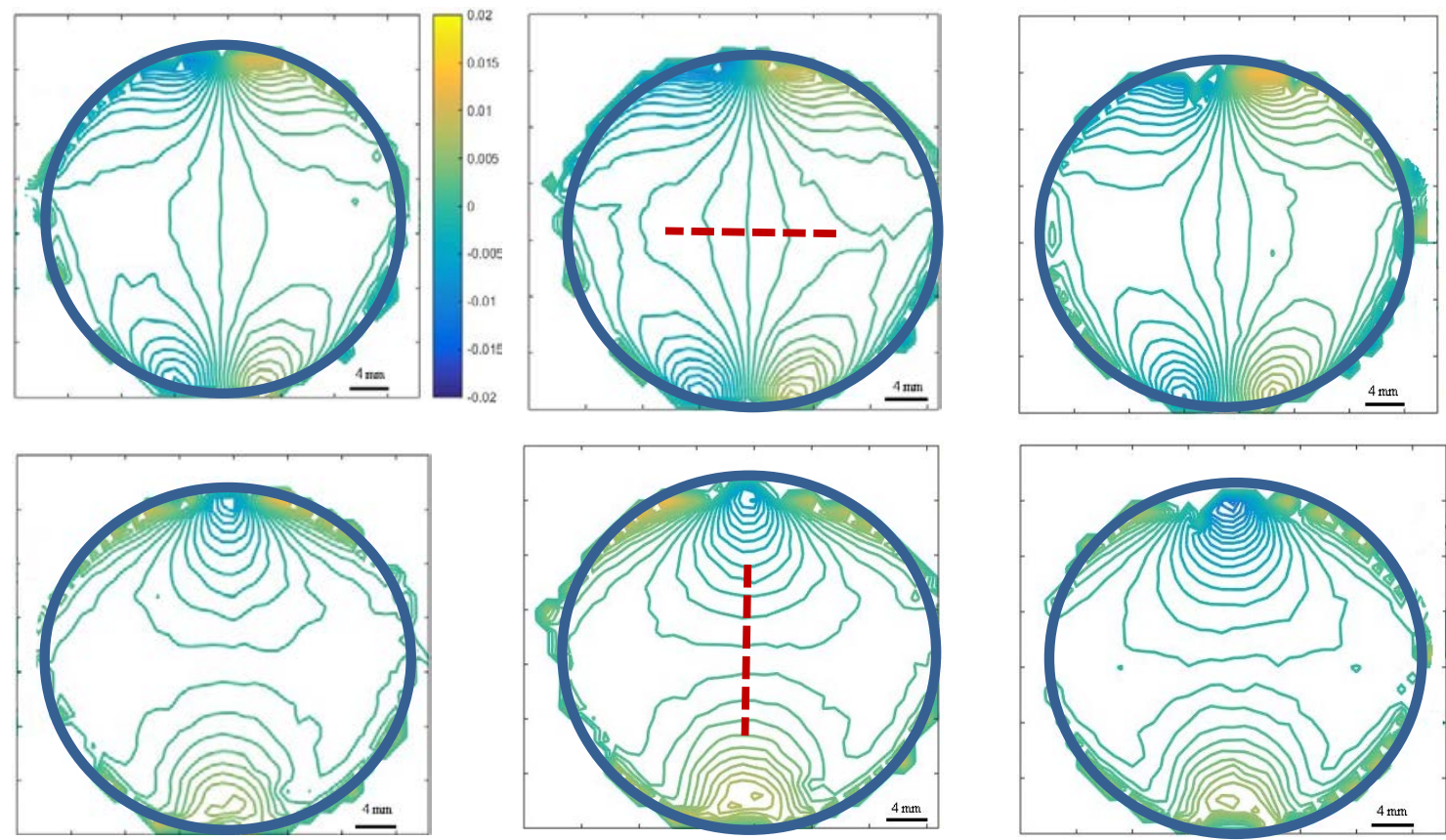

Figure 11: Measured $\phi_{x}$ (top) and $\phi_{y}$ (bottom) contours for a displacement of $1.5 \mathrm{~mm}$ at 0.02 (left), 0.2 (middle) and $2 \mathrm{~mm}$ per sec (right) respectively. Contour interval $=7 \times 10^{-4}$ radian 

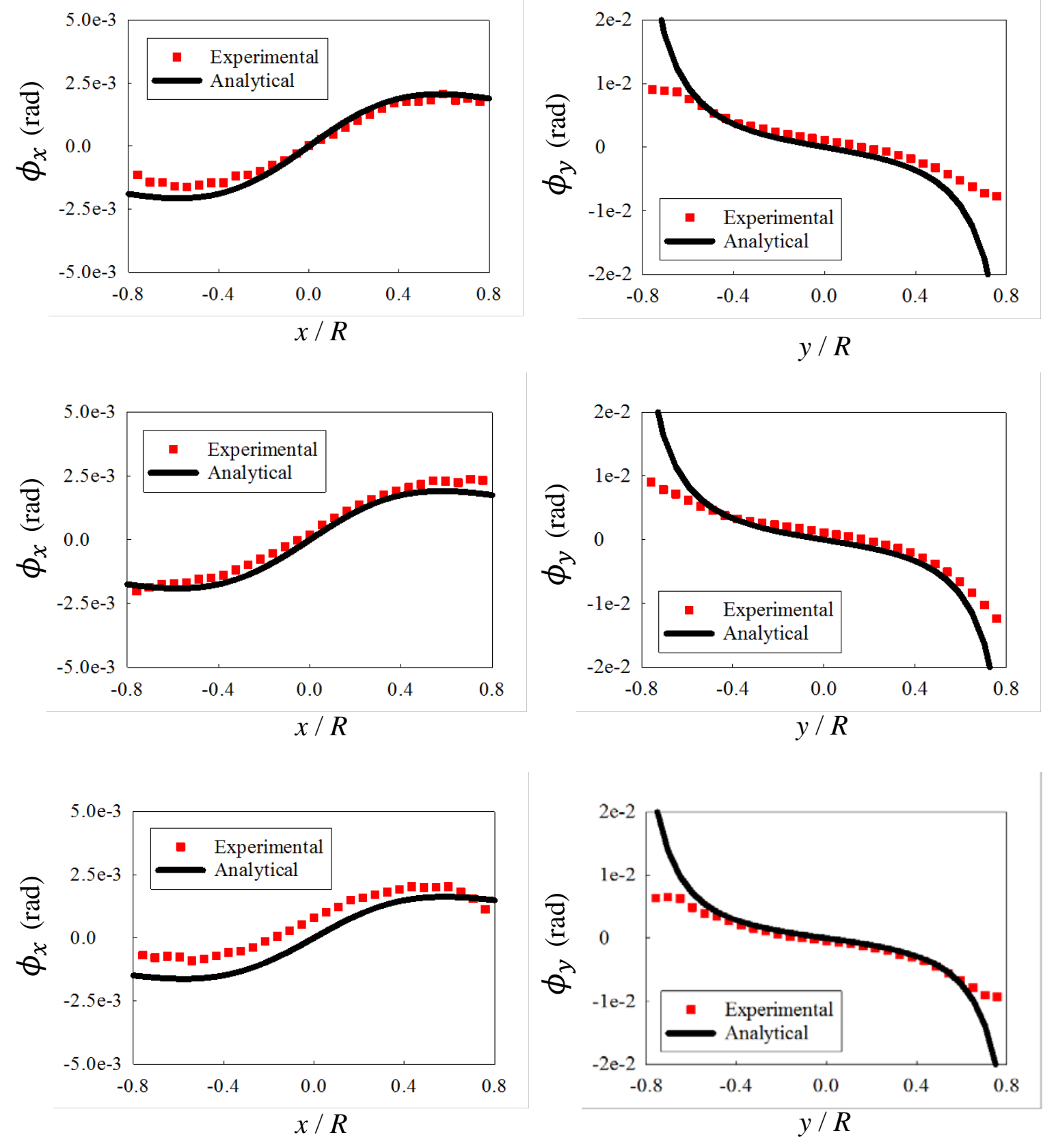

Figure 12: Comparison of experimental (red solid symbols) and analytical (black solid line) $\phi_{x}$ (left) and $\phi_{y}$ (right) values for $0.02 \mathrm{~mm} / \mathrm{sec}$ (top), $0.2 \mathrm{~mm} / \mathrm{sec}$ (middle) and 2 $\mathrm{mm} / \mathrm{sec}$ (bottom) for a load $F=-0.98 \mathrm{~N}$. 

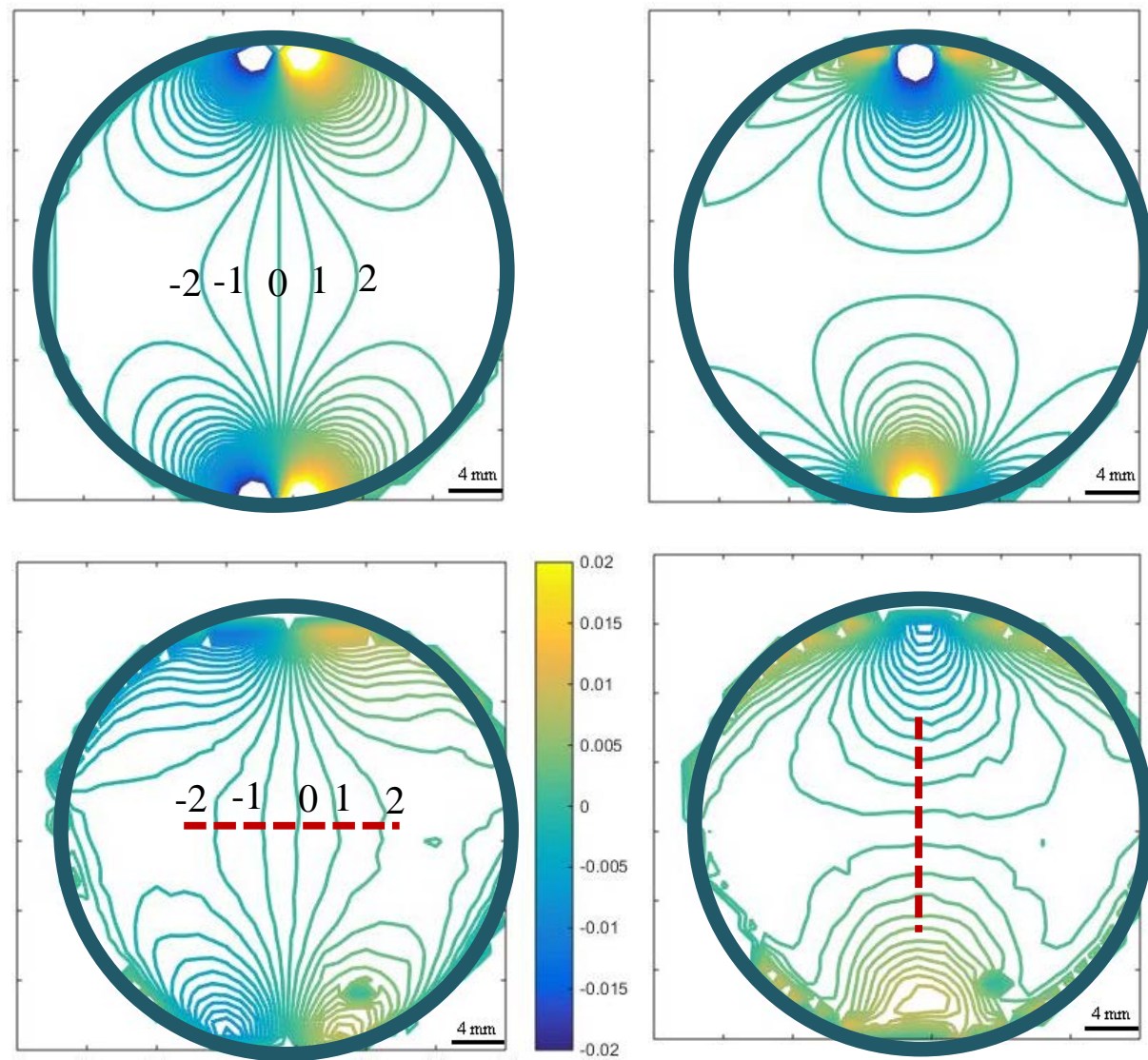

Figure 13: Comparison of analytical (top) and experimental (bottom) $\phi_{x}$ (left) and $\phi_{y}$ (right) contours for $0.02 \mathrm{~mm} / \mathrm{sec}$ case at a load $F=-0.98 \mathrm{~N}$. Contour interval $=7 \times 10^{-4}$ radian. 